\title{
Comments on Effect of Previous Industrial Structure Adjustment In ShanXi Province ZHANG Lu Lu $^{1, a}$ XUE Yao-wen ${ }^{2}$
}

${ }^{1}$ School of Economic and Management, Shanxi Normal University, Linfen 041004,China

${ }^{2}$ School of Economic and Management, Shanxi Normal University, Linfen 041004,China a06090052zhanglu@163.com

Keywords: Industrial structure; Adjustment polices; Effect

\begin{abstract}
Based on the reasons coming from assessment conclusion, the passage evaluate the previous industrial structure adjustment policy implementation effect of ShanXi province. The results show that the previous industrial structure adjusting did not bring significant improvements to ShanXi province. The key reason including constrained by traditional obedience thinking; accustomed to others for their positioning; failed to get rid of the temptation of coal; limited to the immediate and partial economic interests.
\end{abstract}

\section{Introduction}

Shanxi province has been an important base of national energy and heavy chemical industry for 30 years. The exportation of coal and electric power have improved rapidly over the past three decades,along with the increasing deterioration of the ecology, the great fluctuations of economy and the slow growth of people's living standard in Shanxi province. The heavy costs of the development urge us to take measures to achieve the restructuring and upgrade.

The purpose of this paper is to analyze the effects of previous industrial structure adjustment policy's implementation in Shanxi province since 1982. The result will give an effective pre-warning to future developments in Shanxi province regarding policymaking and policy implementation.

\section{The summary of the policy of previous industrial structure adjustment For Shanxi province}

The main purpose of industrial structure adjustment is to realize the rationalization and upgrade of industrial structure ${ }^{[1]}$. Industrial structure adjustment policy is a scientific guidance for the future development of Shanxi province. Figure 1 shows the previous industrial structure adjustment policy of Shanxi province since $1982^{[2]}$. Here is a brief synopsis of my main arguments on the policy.

1. All levels of government deal with the problem with a clear line of thought, but they lack of long-term vision.

2. All levels of government have the rational thought to bail out the pattern of resource dependence, but they lack of courage to give up their position as the national energy and heavy chemical industry base. 
3. Shanxi province has a desire to serve the entire country but cannot save the day by its actual situation.

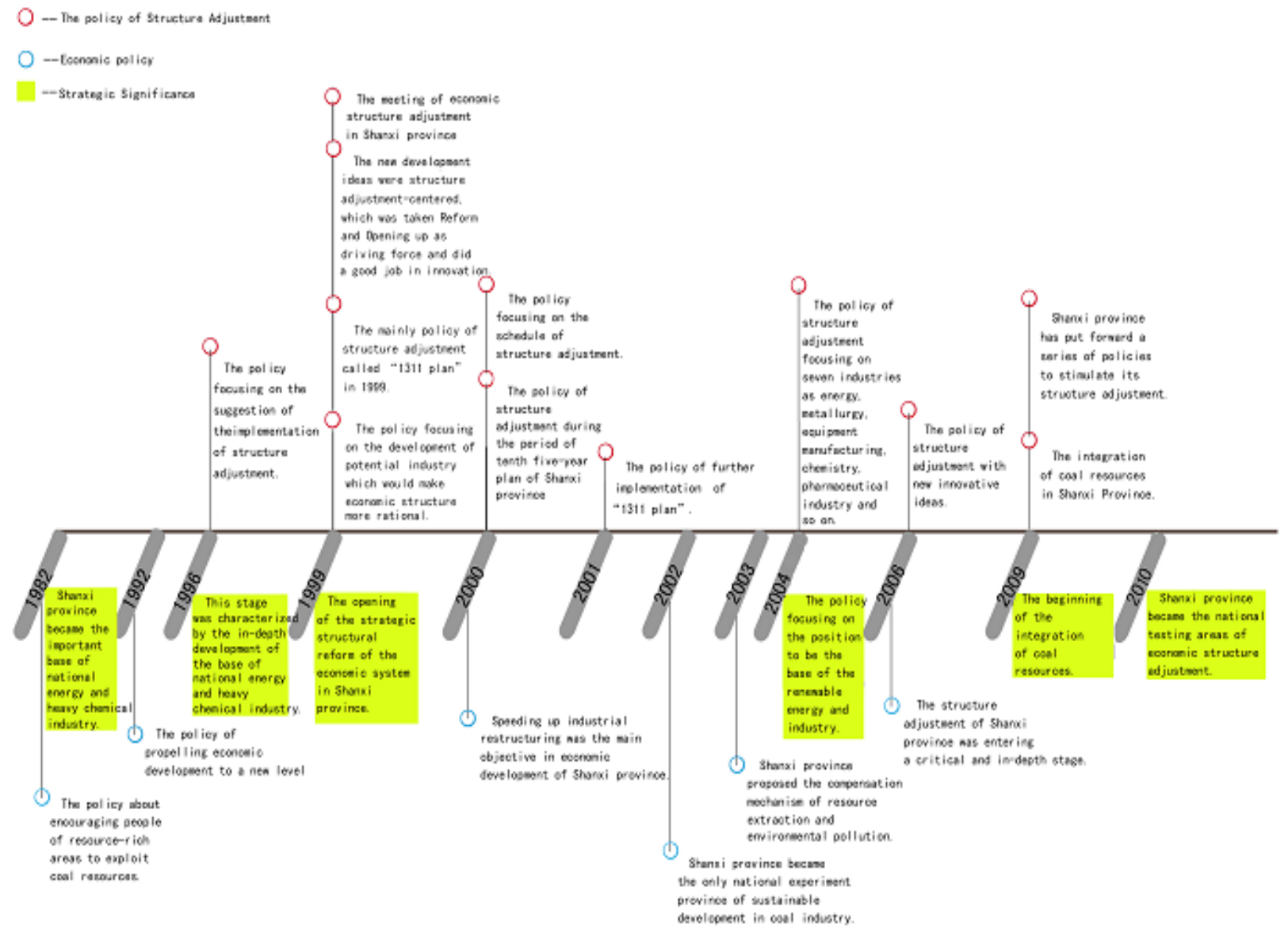

Figure 1 The policy of previous industrial structure adjustment in Shanxi

\section{The evaluation of the effect of policy implementation of Shanxi province previous industrial structure adjustment}

\section{The evaluation of the effect of policy implementation at the economic level}

1. The economic performance of Shanxi province in main years

Figure2 shows,from 1952 to 2011, the GDP of Shanxi province was maintained the trend of sustainable growth. Especially in 2011, it continued to rise at a high pace so that Shanxi province joined the "trillions-GDP club" for the first time ${ }^{[3]}$. From the lateral view, the GDP of Shanxi province is about the size of a developed province like Beijing and Zhejiang province in the 1960s, but its ranking keeps a sustained downward trend in the following years. From the

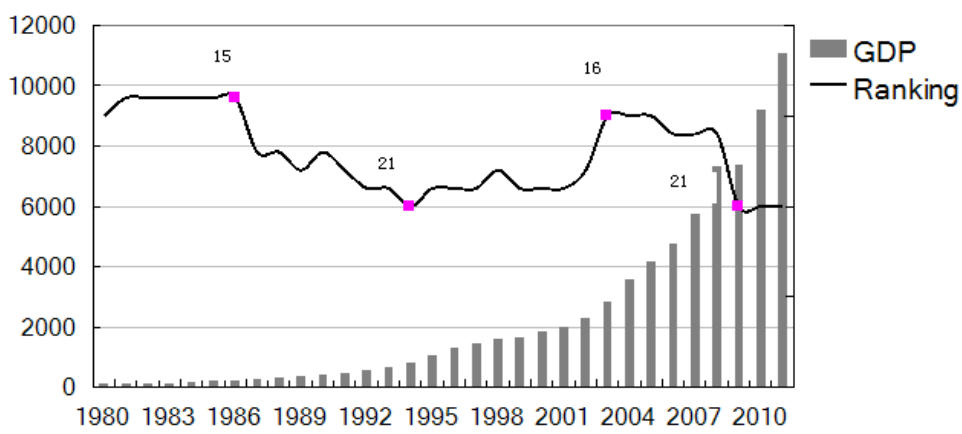

Figure 2 The tendency of GDP in Shanxi province year when the ranking of GDP undulate greatly, the root cause was the risk-resisting ability of energy-based economy is susceptible to the market fluctuation.

2. The proportion of the output of three industries in GDP in main years 
The "main year" in figure3 is selected on the basis of its undergoing the big political and economic fluctuation or the year following some powerful industrial structure adjustment. According to the longitudinal aspect, the proportion of the primary industries of Shanxi province is declining year by year meanwhile the secondary industries' is increasing. The proportion of the service sector is increasing from $20.8 \%$ (1978) to $43.8 \%(2000)$, but it declined again in

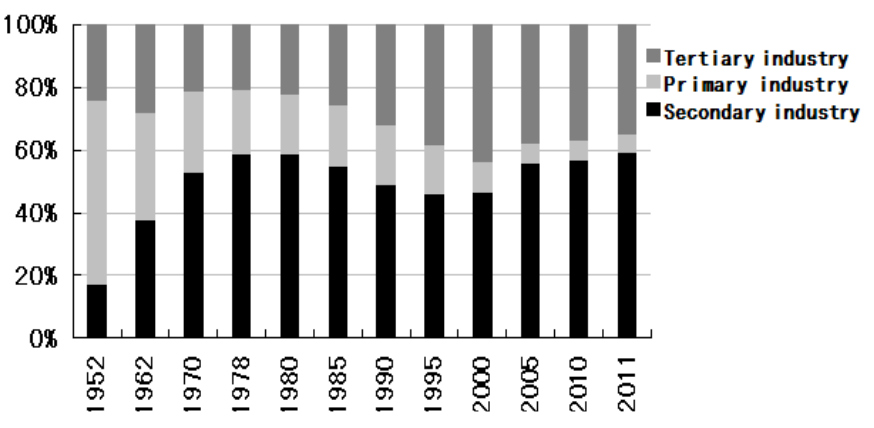

Figure3 The proportion of the output of three industries in GDP of Shanxi province in main years 2010s.

On the basis of the research result from US economist Simon Kuznets, when per capita GDP reaches to $1382 \$$ the more scientific proportion of the service is $40.6 \%$, while the proportion of Shanxi province is about $37 \%$. We may make the conclusion that the development of the tertiary industry of Shanxi province is insufficient.

\section{The evaluation of the effect of policy implementation at the livelihood level}

The government should improve the level of people' material and cultural life. As resources based province, the partial policymaking and implementation will take negative impact on the livelihood of Shanxi province.

1. The analysis of urban households' per capita disposable income

Not only does this evaluation index reflect the policy implementation at the

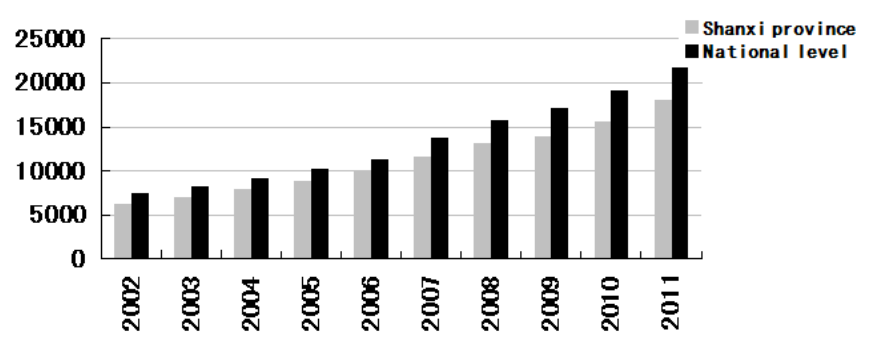

Figure 4 The comparison chart of urban households per capita disposable income livelihood level, but also it can provide reference for future policymaking . As the figure 4 shows the level of urban households' per capita disposable income of Shanxi province is lower than the national average and there is no trend to narrow the gap. The ratio between national level and Shanxi's increased from 100:75 (1995) to 100:88(2006), after then it reduced to 100:82(2010). The level of urban households' per capita disposable income of Shanxi province was somewhat below the national average.

2. The employment of each industry in Shanxi province.

The employment problem is important to the coordinated development and stability of the whole society. The proportion of the number of three industries employed in total employment is another key indicator to measure the industrial structure of a region. Table 1 shows the proportion of the number of primary industry employed, which is higher than other industries, even if this number has fallen considerably.World wide these figures reflect that the lower level of income per capita ,the larger proportion of the number of primary industry employed and the higher the level of income per capita, the larger proportion of the number of tertiary industry employed ${ }^{[4]}$. This employment data suggest that the development of the tertiary industry in Shanxi province is insufficient.

Table1 The proportion of the number of three industries employed in total employment

\begin{tabular}{cccc}
\hline Year & $\begin{array}{c}\text { Primary } \\
\text { industry }\end{array}$ & $\begin{array}{l}\text { Secondary } \\
\text { industry }\end{array}$ & $\begin{array}{c}\text { Tertiary } \\
\text { industry }\end{array}$ \\
\hline 1985 & $48 \%$ & $29 \%$ & $23 \%$ \\
1990 & $47 \%$ & $29 \%$ & $24 \%$ \\
1995 & $44 \%$ & $30 \%$ & $26 \%$
\end{tabular}


3. The comparison of the level of $R \& D$ expenditures between Shanxi province and the whole country.

The rapid development of science and technology and its huge promotion to the socioeconomic development has become one of the main characteristics of this era. The synthesis index which represents the level of

$\begin{array}{llll}2000 & 47 \% & 25 \% & 28 \% \\ 2003 & 44 \% & 25 \% & 31 \% \\ 2005 & 44 \% & 26 \% & 30 \% \\ 2008 & 40 \% & 26 \% & 34 \% \\ 2009 & 39 \% & 26 \% & 35 \% \\ 2010 & 39 \% & 26 \% & 35 \%\end{array}$

Origins of data : National Bureau of Statistics of China technology improvement in 2003 shows that Shanxi province belonged to the fifth class. Even then the government increases input to improve the level of science and technology, the proportion of $\mathrm{R} \& \mathrm{D}$ expenditure in GDP is lower than the national average and the gap have widened from $0.36 \%$ to $0.8 \%$ in the $2010 \mathrm{~s}$.

\section{The evaluation of the effect of policy implementation at the environment level}

The fast development of a resource-based economy is rather easy to see the results of resources being wasted, environmental pollution and other ecological questions. Based on the monitoring air environmental data until 2006, none of cities in Shanxi province attained the Grade II on national standards for air quality. Every ten thousand square kilometers' waste discharge of Shanxi province is significantly higher than the national average, and the trend had not been altered at all. After undergoing the significant restructuring efforts,environmental hazards are not effectively contained.

\section{The reason-analysis of the effect of policy implementation of Shanxi province previous industrial structure adjustment}

\section{The provincial government is affected and dominated by the obedient thought so that it cannot develop on the actual needs.}

In Shanxi province, development is based on the local mineral resources, which regards the resource exploitation as the leading industry. Since Shanxi province became the most important national energy and heavy chemical industry base in 1982, the exportation of energy as coal and electricity has improved rapidly. Cumulative output (for other provinces )of coal over the past years, the data have already amounted to more than 10 billion tons and about $70 \%$ of the country's inter-regional coal distribution quantity. When we analyze the effect of policy implementation, we can conclude that the increasing deterioration of the ecology and the fluctuations of economy are also grim.

2. The provincial government is accustomed to the decision made by the senior so that it cannot develop on the actual needs.

Shanxi province is water deficient. Some experts say the foundation of the national energy and heavy chemical industry base is against the strategy of sustainable development. But the view of "coal resource from Shanxi province must serve the national needs" impelled the establishment of this strategy which restricts the development of Shanxi province all the time ${ }^{[5]}$. The policymaking and implementation have had a negative impact on the development of the new pattern industry all the time. At the same time, the abnormal industrial structure brings negative effect on promoting the development of labor resources on one hand, and produces some brain drain on the other. From the iterative form of policymaking, we are pleased to see the rational and wishful thought to bail out the patterns of resource dependence but lack of determination to break away from the traditional way.

3. Shanxi province lack of courage to give up the great profit brought by coal resources, so

there is no sustained effort to achieve the true meaning of the restructure and upgrading.

In Shanxi province, mining accidents with heavy casualties have occurred frequently which drew great attention from all circles of society, and resulting in a poor reputation. By summarizing the development of Shanxi province in recent decades we can find out a strange phenomenon: although measures of industrial structure adjustment have been put into practice for many years, the worse unreasonable industrial structure still exists. Although policies of developing new pattern industry and protecting environment have been made, the investment proportion of mining industry is always increasing year by year. So the main reason of this serious situation is lack of courage for 
Shanxi province to give up the great profit from coal resources.

4. Shanxi province is confined to the immediate interests and partial interests. And it is necessary to improve the execution of leading cadres.

Such methods are obviously shown in two aspects: the unchanged thinking method of economic development and the limitation of the ability of policymaking and policy execution. The specific performance of unchanged thinking in regarding the GDP as the basis of achievement.These thought lead to the poor effect on policymaking and policy execution. For Shanxi's coal industry, the government attaches too much importance to the quantity rather than quality.And how to solve this probleme? I think these questions are great tests of the execution of leading cadres and a challenge for all policy-makers in the future.

\section{Summary and introspection}

In 2006, a ' Zero Increasing Rate' plan in coal output and 'Negative Increasing Rate' plan in coke output has been carried out. This point was a start of controversy. One view holds that the effective measures to achieve the restructure will be taken soon, while others question who will undertake the national energy supply. The arguments enlighten us to find out the original reason of the underdevelopment. On the one hand the restructure and upgrading will be doomed to fail without controlling the resources production, on the other hand, the provincial government lack of courage to embark on drastic reforms. The new five-year plan for 2011 through 2015 is a new opportunity as well as a challenge for Shanxi province. What Shanxi province has to do is to learn from past experiences,to continue to free our minds on the basis of vital interests of Shanxi province people, and to achieve the real meaning of the restructuring,upgrading and policies put in place.

\section{References}

[1] Chengyu Xu.The research of China's industrial structure adjustment[D].Beijing,Capital University of Economics and Business,2010:9-10.

[2] Fuming Zhang.Sticking to the developing routes to promote structure adjustment [J].ADVANCE,2008(9):12-13.

[3] China Statistical Yearbook [Z].Beijing:China statistical Publishing House,2011.

[4]The World Bank.World Development Indicators 2011[M].Beijing:China Financial \& Economic Publishing House,2011:44-46.

[5]Fuming Zhang.The Road of transformation[M].Taiyuan:Shanxi Education Press,2011:14-15. 